\title{
January Critical Care Case of the Month: Bad Cough
}

\author{
Bhupinder Natt MD \\ Linda Snyder MD \\ Janet Campion MD
}

University of Arizona Medical Center

Tucson, AZ

\section{History of Present IIIness}

A 41 year-old man was admitted with a five-day history of cough, shortness of breath, and fever to $102^{\circ} \mathrm{F}$. He was recently diagnosed with a high-grade astrocytoma of the brain and had undergone resection followed by chemotherapy with temozomide (an alkylating agent) and radiation therapy.

\section{$\mathrm{PMH}$}

- Renal transplantation (1993)

- Glioblastoma (astrocytoma grade 4)

- Crohn's disease treated with budesonide and meselamine

\section{Medications}

- Dexamethasone $2 \mathrm{mg}$ PO BID

- Keppra 500 mg PO BID

- Tacrolimus $1.5 \mathrm{mg}$ PO AM and $1 \mathrm{mg}$ PO PM

- Mycophenolate $750 \mathrm{mg}$ PO BID

- Budesonide $3 \mathrm{mg} P O$ daily

- Meselamine $1600 \mathrm{mg}$ PO TID

- Sulfamethoxazole/trimethoprim DS PO on Mon/Wed/Fri

- Temozolomide $75 \mathrm{mg}$ IM with radiotherapy

\section{Social History}

Nonsmoker, no ethanol or recreational drugs, no recent travel, and no occupational exposures.

\section{Physical Examination}

T 38.6 ${ }^{\circ} \mathrm{C}, \mathrm{P} 112$ beats/min, RR 32-40 breaths/min, BP 119/76 mm Hg, SpO2 $100 \%$ on NRB

General: Fatigued, ill appearing and dyspneic.

Skin: No rash or lesions, well-healed craniotomy scar

HEENT: Dry oral mucosa, pupils and extra-ocular muscles normal

Respiratory: Reduced breath sounds, fine crackles throughout all lung fields, no wheezing

CVS: Hyperdynamic precordium, tachycardia without murmur, no elevation of jugular venous pressure (JVP), peripheral vascular exam normal.

Abdomen: Soft, non-distended, no hepato-splenomegaly, normal bowel sounds. Lymph: No cervical lymphadenopathy 
Extremities: No edema, normal muscle bulk and tone.

\section{Laboratory}

WBC $11 \times 10^{3} / \mu \mathrm{L}$, Hemoglobin $9.8 \mathrm{~g} / \mathrm{dL}$, Hematocrit $30 \%$, Platelets $264,000 / \mu \mathrm{L}$ $\mathrm{Na}^{+} 135 \mathrm{meq} / \mathrm{L}, \mathrm{K}^{+} 4.2 \mathrm{meq} / \mathrm{L}, \mathrm{Cl}^{-} 111 \mathrm{meq} / \mathrm{L}, \mathrm{CO} 214 \mathrm{mmol} / \mathrm{L}$, blood urea nitrogen (BUN) $46 \mathrm{mg} / \mathrm{dL}$, creatinine $1.7 \mathrm{mg} / \mathrm{dL}$, glucose $132 \mathrm{mg} / \mathrm{dL}$, calcium 10.5 $\mathrm{mg} / \mathrm{dL}$, albumin $1.5 \mathrm{~g} / \mathrm{dL}$, liver function tests-within normal limits Prothrombin time (PT) $15 \mathrm{sec}$, international normalized ratio (INR) 1.2, partial thromboplastin time (PTT) $29.9 \mathrm{sec}$

Chest X-ray
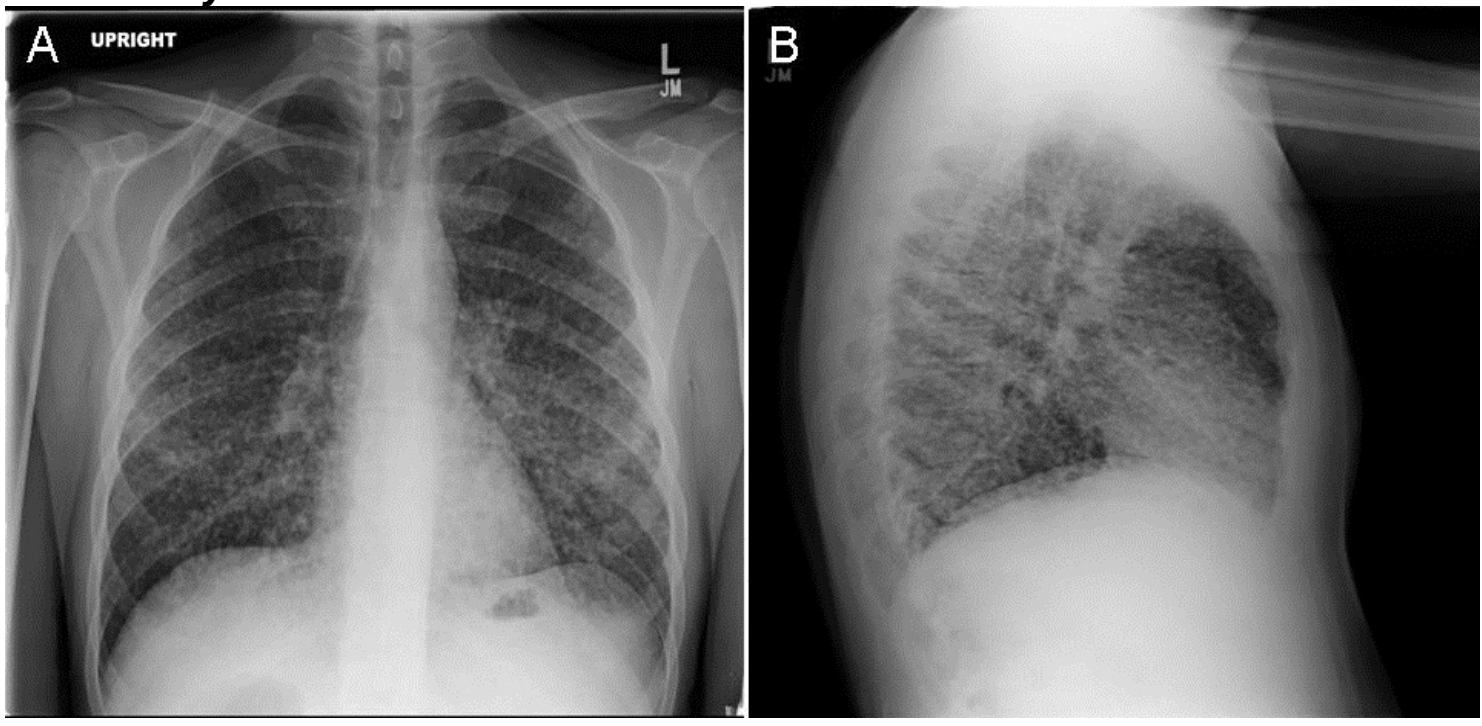

Figure 1. Admission PA (Panel A) and lateral (Panel B) chest x-ray.

What is the best description of the chest x-ray?

1. Bibasilar consolidation

2. Bilateral diffuse nodules

3. Pneumomediastinum with subcutaneous emphysema

4. Pulmonary edema with evidence of pulmonary hypertension

5. Subdiaphragmatic free air 


\section{Correct! \\ 2. Bilateral diffuse nodules}

The chest $x$-ray shows small, bilateral diffuse nodules measuring 1-3 mm consistent with a miliary pattern.

Which of the following is not included in the differential diagnosis of miliary pulmonary disease?

1. Acute extrinsic allergic alveolitis

2. Histoplasmosis

3. Penicillin exposure

4. Sarcoidosis

5. Thyroid cancer 


\section{Correct!}

\section{Penicillin exposure}

The differential diagnosis of a military pattern on chest $\mathrm{x}$-ray does not typically include medication side effects. The differential is extensive including 1) Infectious: disseminated fungal disease, tuberculosis and viral pneumonias due to cytomegalovirus (CMV) and varicella; 2) Inhalational diseases such as silicosis, extrinsic allergic alveolitis, and other pneumoconioses; 3) Malignancy from bronchoalveolar carcinoma as well as hematogenous lung metastasis from lung, thyroid, renal cancers; and 4) Others including sarcoidosis and pulmonary hemosiderosis (1).

The patient was transferred to the ICU and was intubated and placed on mechanical ventilation. Initial basic metabolic panel (BMP), arterial blood gases $(A B G)$, and ventilator settings are as follows:

BMP: $\mathrm{Na}^{+} 135 \mathrm{meq} / \mathrm{L}, \mathrm{K}^{+} 4.2 \mathrm{meq} / \mathrm{L}, \mathrm{Cl}^{-} 111 \mathrm{meq} / \mathrm{L}, \mathrm{CO} 214 \mathrm{mmol} / \mathrm{L}$, blood urea nitrogen (BUN) $46 \mathrm{mg} / \mathrm{dL}$, glucose $132 \mathrm{mg} / \mathrm{dL}$, albumin 1.5 $\mathrm{g} / \mathrm{dL}$

ABG: pH 7.16, pCO2 38 mm Hg, pO2 95 mm Hg, HCO3- 13 meq/L, SaO2 $95 \%$.

Ventilator settings: Assist control/volume control (ACVC) with respiratory rate (RR) set at 20 with actual rate of 40 , positive end expiratory pressure (PEEP) $8 \mathrm{~cm} \mathrm{H} 20, \mathrm{FiO} 250 \%$, tidal volume (TV) $400 \mathrm{ml}$ with ideal body weight 76 kgs.

What is the acid-base status and how might you adjust the ventilator to improve this acid base status?

1. Metabolic gap acidosis and respiratory acidosis; increase PEEP

2. Metabolic gap acidosis and respiratory acidosis; increase RR

3. Metabolic gap acidosis, metabolic alkalosis, respiratory acidosis; increase $\mathrm{RR}$

4. Metabolic gap and non gap acidosis, respiratory acidosis; increase TV

5. Metabolic gap and non gap acidosis, respiratory alkalosis; increase TV 


\section{Correct!}

\section{Metabolic gap and non gap acidosis, respiratory acidosis; increase TV}

- The Henderson-Hasselbalch equation $\left(\mathrm{pH}=6.1+\log \left[\mathrm{HCO}^{-} / 0.03 \times \mathrm{pCO} 2\right]\right)$ shows $\mathrm{H}+=65$, consistent with a pH of 7.18

- Metabolic acidosis by $A B G$ with an anion gap $\left(\left[\mathrm{Na}^{+}\right]-\left[\mathrm{Cl}^{-}+\mathrm{HCO}_{3}{ }^{-}\right]\right)$of 10 but when adjusted for albumin (2.5 decrease in anion gap for every gram drop in albumin below 4 ) the normal anion gap is decreased to approximately 4 and therefore the anion gap is elevated.

- Delta ratio ([measured anion gap - normal anion gap] / [24 - $\left.\mathrm{HCO}_{3}{ }^{-}\right]$) of approximately 0.6 also shows a non anion gap metabolic acidosis. A delta ratio below 1 indicates a greater fall in [HCO3-] than one would expect given the increase in the anion gap. This can be explained by a mixed metabolic acidosis, i.e., a combined elevated anion gap acidosis and a normal anion gap acidosis.

- Winter's formula (expected pCO2 $=\left[1.5 \times \mathrm{HCO}^{-}\right]+8$ ) shows an expected pCO2 of 29 which is lower than the measured 38 suggesting a coexisting respiratory acidosis.

- Increasing the TV with his existing RR of 40 will increase ventilation to maximize ventilator correction of his respiratory acidosis until the metabolic acidosis can be corrected. You must carefully monitor the peak and plateau pressures as this patient would be at high risk for pneumothorax.

What would be reasonable empiric antibiotic coverage for this patient?

1. Amphotericin and ceftriazone

2. Vancomycin and piperacillin/tazobactam

3. Vancomycin, piperacillin/tazobactam, azithromycin, sulfamethoxazole/trimethoprim, fluconazole

4. Vancomycin, piperacillin/tazobactam, azithromycin

5. Vancomycin, piperacillin/tazobactam, trimethoprim/sulfa 


\section{Correct! \\ 3. Vancomycin, piperacillin/tazobactam, azithromycin, sulfamethoxazole/trimethoprim, fluconazole}

This patient is at risk for hospital-acquired, resistant, opportunistic and endemic infections. Antimicrobials against methicillin-resistant Staphylococcus aureus (MRSA), Pseudomonas, atypical bacteria, pneumocystis and coccidioidomycosis are required in this case.

His bronchoalveolar lavage cytology revealed spherules consistent with Coccidioidomycosis immitis and treatment was changed to IV voriconazole, lipid amphotericin, piperacillin/tazobactam, and sulfamethoxazole/trimethoprim prophylaxis after cultures showed no MRSA.

The platelet count on admission was $264,000 / \mu \mathrm{L}$ but five days later had decreased to $63,000 / \mu \mathrm{L}$. He had no other significant changes in laboratory values from admission. The patient was not on subcutaneous heparin prophylaxis given the concern for residual glioblastoma tumor and risk of intracerebral hemorrhage.

Which of the following is (are) a likely etiology (etiologies) for the thrombocytopenia?

1. Disseminated intravascular congestion

2. Heparin induced thrombocytopenia

3. Thrombocytopenic purpura

4. Trimethoprim/sulfamethoxazole side effect

5. 3 and 4 


\section{Correct!}

\section{3 and 4}

He has risk factors for thrombotic thrombocytopenic purpura/hemolytic uremia syndrome (TTP/HUS) given his history of renal transplant with a tacrolimus side effect and having an underlying malignancy although adenocarcinoma is the more typical malignancy associated with TTP/HUS. He may also have developed an acquired ADAMTS13 (a disintegrin and metalloproteinase with a thrombospondin type 1 motif, member 13-also known as von Willebrand factorcleaving protease) deficiency. In addition, he is at risk for medication induced thrombocytopenia from bone marrow suppression with use of trimethoprim/sulfamethoxazole, tacrolimus and mycophenolate. The ADAMTS13 level was within normal range, not $<5 \%$ which would be associated with acquired TTP. His peripheral smear showed a few schistocytes but not enough to diagnose a microangiopathic hemolytic process. His thrombocytopenia was determined to be drug related bone marrow suppression and his counts eventually improved without intervention.

\section{References}

1. Furgan M, Butler J. Miliary pattern on chest radiography: TB or not TB? Mayo Clin Proc. 2010;85(2):108. [CrossRef] [PubMed]

2. Nguyen C, Barker BM, Hoover S, Nix D, Ampel NM, Frelinger JA, Orbach MJ, Galgiani J. Recent advances in our understanding of the environmental, epidemiological, immunological, and clinical dimensions of coccidioidomycosis. Clin Micro Rev. 2013;26(3):505-25. [CrossRef] [PubMed] 